\title{
الترادف في اللغة العربية
}

\author{
Masnal Zajuli \\ Jurusan Pendidikan Bahasa Arab Fakultas Tarbiyah IAIN Imam Bonjol Padang \\ Korespondensi: Jln . Mahmud Yunus Lubuk Lintah Padang
}

\begin{abstract}
Arabic has unique characteristics which are found in other languages. This makes Arabic a flexible language and has high of elasticity. As a result, in fulfilling and maintaining its function as a means for communication, a medium of delivering Islamic information, a tool for recording of knowledge, Arabic has been able to carry out them very well. However, due to its nature, discussing about Arabic cannot be separated from sounds and meanings since language is basically sounds which produced by the speaker to reveal his thoughts and feelings to achieve particular purposes. Sounds (lafaz) are limited while meanings develop in line with the development in science and technology. As a result, the more findings have been made, the more meanings are required to reveal the findings. In this context, the phenomena of single sound implies several meanings or one meaning required more sounds in Arabic are known as isytirak al-lafzi wa almaknahu wa al-tuudad. Further and deeper studies need to carry out to avoid the possible mistakes in expressing meanings of Arabic words, especially those of the Holy Quran.
\end{abstract}

Kata kunci: لغة , ترادف

الكلمة يستوجب النظر في خصائصها المعجمية

مقدمة

والتركيبية والصرفية والصوتية والبلاغية والدلالية.

بخصوص ما يتعلق بظاهرة الترادف التي دعتنا إلى

أن نأخذها بعين الاعتبار في إعطاء المعنى المقصود

من اللفظ وذلك لأن الخطاء في اعطاء المعنى يفسد المفهوم الصحيح من العبارات.

وقد إخترنا هذا الموضوع للدراسة والتحليل

لأهميته في كونه موضعا يمكن أن يتطور فهمنا

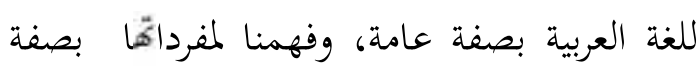

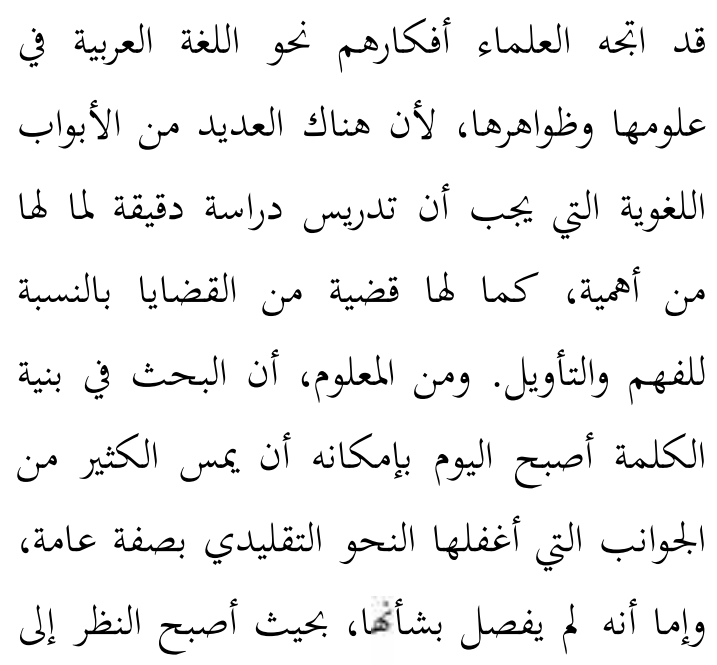


كلمات القرآن الكريم. لعل البحث يدافع القراء الكرام ومن يهمه الأمر به في ترقية العناية نحو اللغة العربية بغية الحصول إلى اتقائها على أحسن

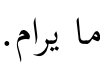

نخن نحاول في هذا البحث الدراسة والتحليل عن الترادف لنروم الجواب من الأسئلة: ما هي اللغة العربية، لماذا نحتاج إلى اللغة، وما هو الترادف وكيف وجوده في اللغة العربية، وما هي العلاقة بينه وبين الدلالة. نتمنى أن يكون البحث مفيدا لكشف المعلومات نهو الترادف في اللغة العربية كما يستفيد به القرآ الكرام ومن يهمه الأمر نحو أهمية عن الدلالة في اعطاء معنى الكلمات التي دخلت في هذه الظاهرة.

إن المسألة الأساسية التي تروم الدراسة والتحليل عنها هي: اطلاق معنى واحد لعدة كلمات في اللغة العربية نحن نريد أن ندرس ونحلل هذه الظاهرة اللغوية، راجعا أن تكون الدراسة إزالة عن اللبس والغموض في اعطاء معنى الكلمات التي دخلت هذه الظاهرة، للرد على الأسئلة، ما هي اللغة العربية ولماذا نحتاج إلى اللغات، وما هو الترادف ووجوده في اللغة العربية وما لعلاقته بينه والدلالة.

حيث الدراسة والتحليل عن الموضوغ السابق الذكر في معالحة بعض العلاقات المفترضة بين ظاهرة الترادف وظواهر لغوية أخرى ذات صلة وثيقة لها، راجيا أن يكون البحث له فائدة لكشف المعلومات عن الترادف في ظاهرته وأهميته قيل تحديد المعنى من اللفظ الذي دخل هذه
خاصة. وذلك لأن قضية اللفظ والمعنى في اللغة العربية معرقة ومعقدة، وتطرح العديد من الأسئلة الجوهرية التي يدور حولما الخلاف حسب الآراء المذهبية و الأسس النظرية المستعملة في التحليل. فمن ناحية المفردات مثلا: لها ظاهرة من الظواهر. يقول السيوطي: "بأنه اللفظ الواحد الدال على لي لئ معنيين مختلفين فأكثر دلالة على السواء عند أهل تلك اللغة"(السيوطي: 379 1986 هذه الظاهرة هي ما اصطلحه علماء اللغة بالاشتراك المعنوي أو الترادف. فالاكثرون منهم قد ذهبوا إلى ممكن وقوع هذه الظاهرة في اللغة، وذلك: بأن يضع أحدهما واضع لفظا لمعنى، ثم يضعه الآخر لمعنى أخر، ويشتهر ذلك اللفظ بين الطائفتين في إفادمّا المعنيين، وهذا أن اللغات غير توقيفيف. بجانب ذلك أن المعاني غير متناهية، واللفظ على عكسه. إن خصوصية دراسة ظاهرة الترادف تتجلى أكثر في أخلا باستطاعتها أن تزيل بعض الليس والغموض في إعطاء المعنى من الكلمات. وذلك أن فهم هذه الظاهرة يعني فهم وتفسير بحموعة من الظواهر الأخرى التي لها صلة متينة بالكلمة وخصائصها المختلفة. بجانب وجود قضايا المعنى في اللغة العربية التي تحتاج إلى الدراسة والتحليل والتي تطرح العديد من الأسئلة الجوهرية التي مازال الخلاف يدور حولها، ب بخصوص ما يتعلق بالترادف. هذه كلها دفعتنا إلى البحث عن الترادف إزالة لبعض الغموض الذي يسبب الخطاء

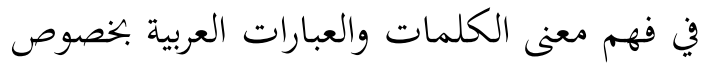


بعد ما حدث سيل العرم ومن أمهاتمم كهالان وحمير. وأما العرب المستعربة فهم بنو إسماعيل

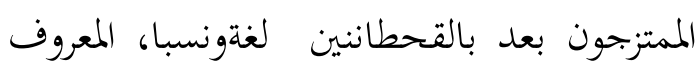

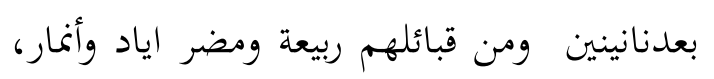
هذا التقسيم بقي الآن ما سمي بالعرب البائدة والباقية.

قد حرص علماء اللغة على أخذ اللغة

متونها وأساليبها من الأعراب سكان البوصن البهادي.

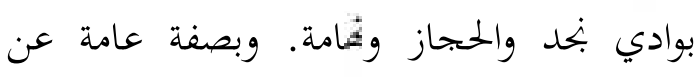

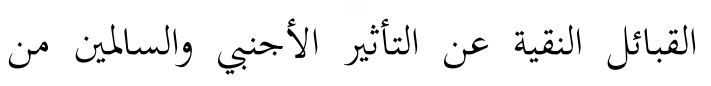
أفصح فساد السلائق ولجوئها بمساكنة الأعاجم. يقول مصطفى صادق الرافعي: " إن قريشا كانوا أفصح العرب ألسنة، وأخلصهم لغة، وأعذهم الرفم

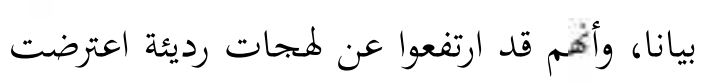
في مناطق العرب، فسلمت بذلك لغتهم، وإنما كان هؤلاء القوم انضاض النبي صلى الله عليه

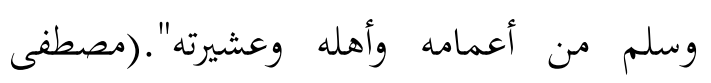

صادق الرافعي: 1973: 315

قد تحدث عن اللغة العربية في نشأتما وتطورها وعلومها وأهمية معرفتها، كثير من العلماء

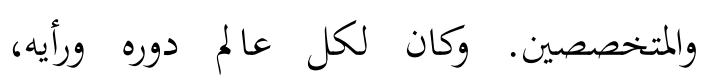
اجتهادا منهم نحو هذه اللغة. وذلك على وجود ولمان

$$
\text { المزايا منها مالم توجد في اللغة الأخرى. }
$$

إننا لو نظرنا بعدل وحكمة إلى هذه اللغة، لوجدناها أفضل وأشرف اللغات على الإطلاق وذلك لعدة أسباب منها: أ- إن اللغة العربية التي نزل بما القرآن الكريم

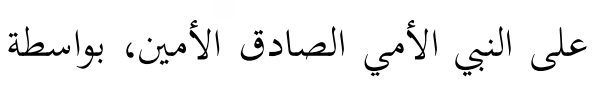

الظاهرة كما يستفيد منه القراء الكرام ومن يهمه الأمر في نهو الكلمات العربية التي تحتاج إلى الى الكراء التدقيق قيل إعطاء معناها بمراعات الدلالة التي لتئي تدل على المعنى المقصود. بغية الحصول على المعنى الصحيح ازالة عن اللبس والغموض، ولا سيما

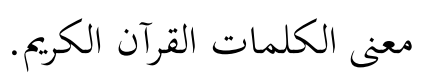

\section{اللغة العربية وحاجاتنا إلى اللغة}

قد اتفق الرواة أن اللغة العربية لغة سامية،

وهي لغة منسوبة إلى سام ابن نوح عليه السلام

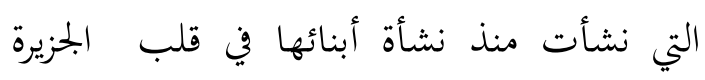

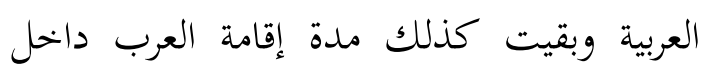

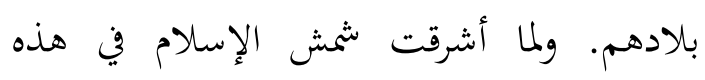

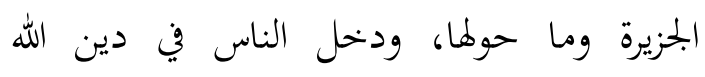

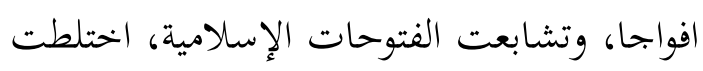

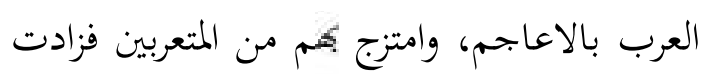

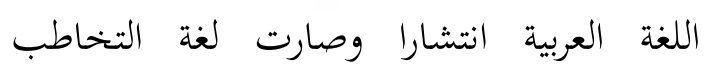
والتعامل حتى يتكلم بالعربية غير العرب، وابته التهابل أفكارهم في الدراسة عنها. وهي الآن من اللغات الرسمية في العالم، ستبقى أبدا الدهر ببقاء القرآن

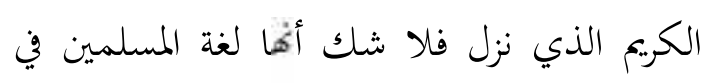

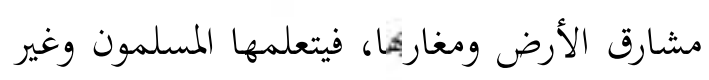
المسلمين في أمور شيء. اتفق الرواة وأهل الأخبار على تقسيم

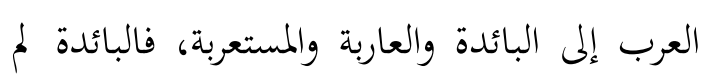
يصل الينا اخبارهم الا ما قصه الله تعالى في القرآن

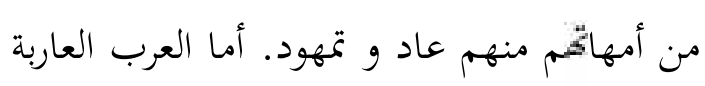
فهم بنو قحطان الذين انتشرت في انحاء الجزيرة 
ج- إن اللغة العربية هي لغة الحضارة والتقدم والرقي والازدهار . والدليل على ذلك تلك الحضارة الاسلامية التي كانت في الأندلس في أواخر العصر الأموي، كان التأليف والتدوين والترجمة في مختلف نواحي العلوم الإسلامية واللغوية والأدبية والعلمية من فلك وهندسة وطب ورياضيات وكيمياء وفيزياء وغيرها من العلوم مكتوبة ومدونة باللغة العربية هذه كلها قد شجلها التاريخ.

مما لا شك فيه أننا تحتاج إلى اللغة في تعبير ما خطر في بالنا لسد لوازم حياتنا اليومية بغية

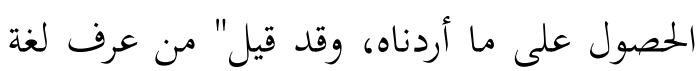
قوم آمن من مكرهم" كانت الوظيفة الأساسية للغة، وسيلة من الاتصال في التعبير عن طريق الأصوات الكاملة. اللغة كما عبره محمود السعران "وأن ما توصله اللغة او تنقله أو تعبر عنه، هو ال هيره الأفكار والمعاني والرغبات والانفعالات. أو الفكرة بوجه عام " (محمد السعران : 1923: 12) في بحال التعليم مثلا نحن نرى هذه الوظيفة في جمع عدة المعلومات الهامة في شتى العلوم بعدة اللغات.

إن اللغة وسيلة تسهل بها الفكر وتساعد على نموه. وهذا النمو قد تطورت اللغة نفسها، وذلك لأن التفاعل بين اللغة والفكر أمر لا نقاش ولث لهرك فيه. نحن نفكر بجممل واللغة هي التي وعاء للفكر بين التهر وبالعكس فلا يوجد الفكر إلا باللغة. وباللغة يسجل المؤرخون تاريخ الشعب، بهذا التاريخ
جبريل من عند رب العالمين. ولا شيء

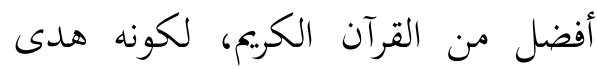
للناس وبينات من الهدى والفرقان. فمن تمسك به وعمل بتعاليمه، فله السلامة الأبدية في الدارين. كما أشار إليه قوله تعالى: يا أيها الناس قد جاء تكم موعظة من ربكم وشفاء لما في الصدور وهدى ورحة للمؤمنين- قل بفضل الله وبرحته

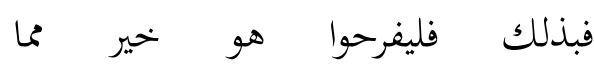
58-57: يجمعون"(يونس 10 ب-إن اللغة العربية لغة لغة باقية إلى يوم الدين، وذلك ببقاء القرآن الكريم الذي نزل بها. كما أشار إليه قوله تعالى: "إنا نحن نزلنا الذكر و وإنا له لحافظون". (الحجر:15 :9 :9 فاللغة العربية لغة القرآن الكريم، وأن الله تعالى هو الذي يحفظه عن التبديل والتحويل إلى قيام الساعة. إذن فاللغة العربية ستظل باقية إلى يوم الدين. فالمشكلة العارضة في هذه اللغة اليوم، بخصوص لمن يتكلم بها كلغة الأم، "أن العربية الفصيحة المكتوبة هي غير العربية المستعملة في التخاطب". (إبراهيم السامرائي: 1987 : 28) هذا معناه أن اللغة العربية الفصحى قلة الاستعمال في البحاملة اليومية حتى في الإدارة والجامعة. كما لاحظ الباحث في المغرب مثلا، أن الدارجة قد غلبت الفصحى في البحاملة اليومية. 


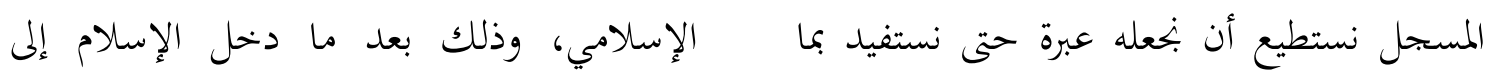

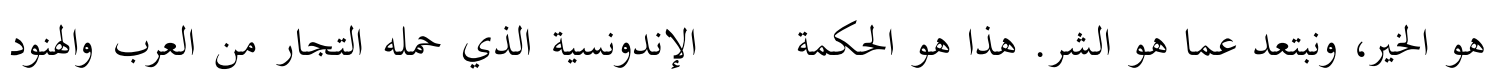

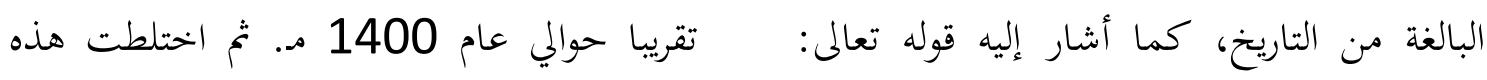

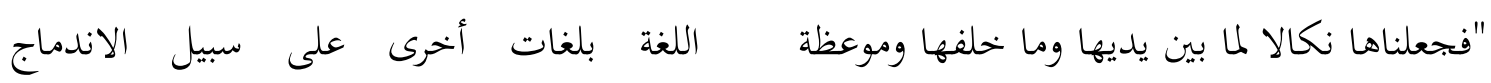

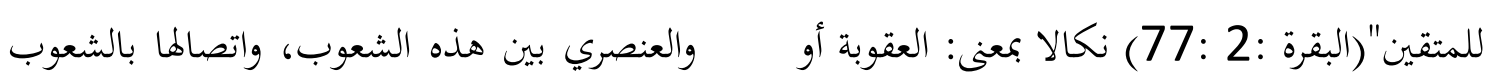

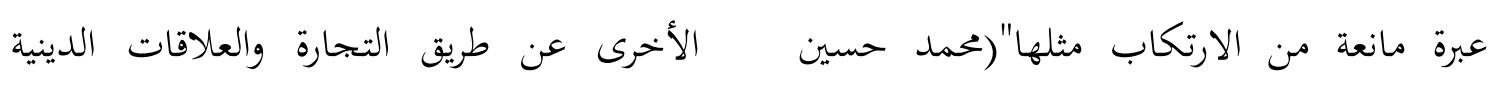

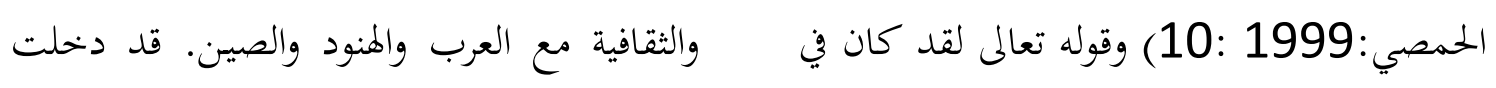

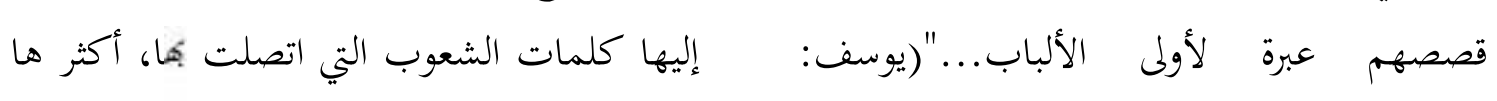

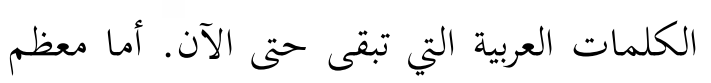
الأندونيسيين يفهمون باللغة الإندونيسية كلغة الان التهات

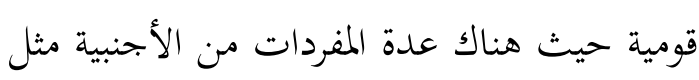

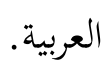

إن اللغة مادة تظهر البتمع الإنساني على حقيقته، وهي وثيقة الصلة بالإنسان وبيئته، فاللغة الإنة

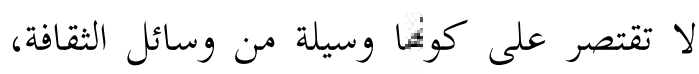

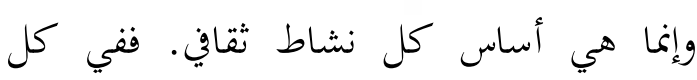

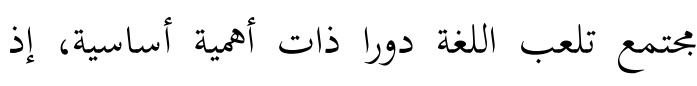

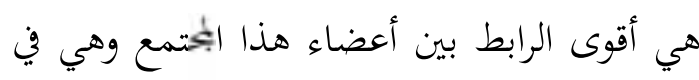

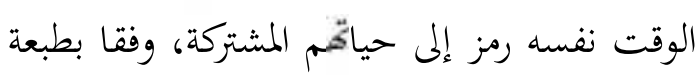
الإنسان على أنه مدني بالطبع، خلقه الله سبحانه

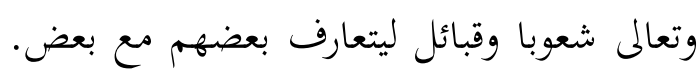

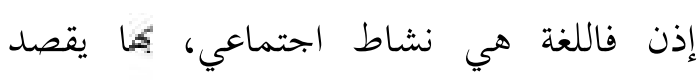

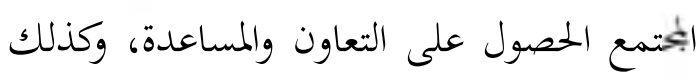
في إقامة الود والألفة بين المواطين. هكذا رأينا وظيفة اللغة في الحياة البشرية. ومن هنا تبين لنا أن معرفة اللغة لها أهمية كبرى في الهياه اليترية تحصيل ما أردناه من المقاصد واللوازم، التي نختاج

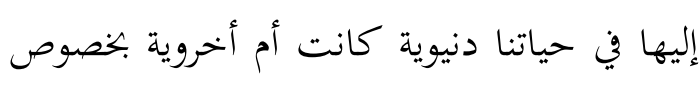

هكذا شأن اللغة حيث لها علاقة قوية بحياة الشعب، وهي تساعد على نمو الفكر والتعبير عما خطر في البال، وفقا بطبيعة الإنسان

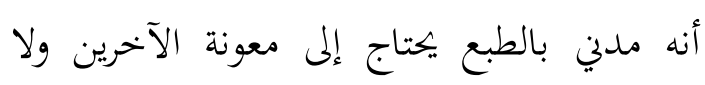
يمكن أن يعيش منفردا. تبادل الآراء والأفكار بينه

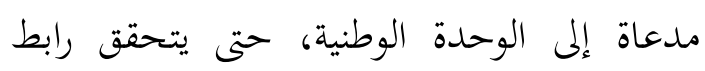

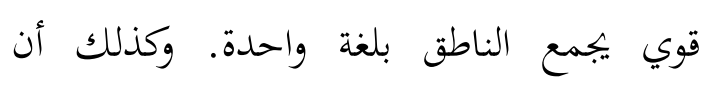
اللغات المختلفة في الأمة الواحدة مدعاة إلى واحلى وكدلى ان

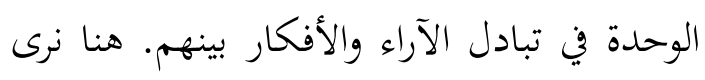
حكمة من خلق الناس شعوبا وقبائل ليتعارفوا. كما أشار إليه قوله تعالى: " يا أيها الناس إنا خلقناكم من ذكر وأنثى وجعلناكم شعوبا وقبائل لتعارفوا إن أكرمكم عند الله أتقاكم إن الله عليم وانيم

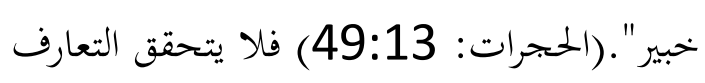
المقصود إلا باللغة. كان الترابط الدولي والقومي، ثروة لغزيرة مفردات اللغة. في اللغة الإندونسية مثلا، فاللغة الغران الجوية هي التي شاعت في الجزر الإندونسية وما جاورها، ثم حلت مكاثما الملايوية في العصر الإني 
والغموض. تعمل جاهدة على وضع نميزات، وخصائص لتزيل بموجبها ذلك اللبس وتكشف لهف هذا الغموض. وقال المستشرق الكبير بروكلمن: تمتاز لغة الشعر العربي بثورة واسعة في الصور النحوية (الإعراب)، وتعد أرقى اللغات السامية تطورا من حيث تركيبات الجمل ودقة التعبير. أما المفردات فهي فيها غنية يسترعى الانتباه، ولا بدع

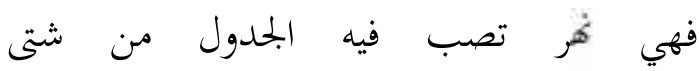
القبائل".(حنا الفاخوري:1987 :25 ) كانت اللغة العربية شفيعة التعبير، وذلك بأن فيها لغة فصيحة يتوخاها الكاتب في كتابته

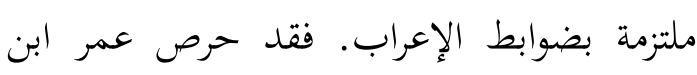
الخطاب رضي الله عنه على الأحذ بقراءة القرآن الكريم التي تعتمد على لغة قريش، واجتهد عثمان ابن عفان رضي الله عنه جمع القرآن ليكون

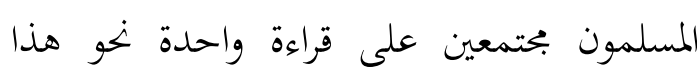
الكتاب العظيم.

ومن نميزات اللغة العربية أيضا، أثما تتميز بالفني الصريف الذي يجعلها تعبر عن مختلف الدلالات بلواصق صرفية مختلفة. أحيانا يكون لها

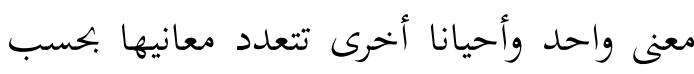
استعمالاكما. وهي أيضا من هذه الناحية لم يتم فيها توسيع المعنى بإضافة اللواصق الصرفية إلى

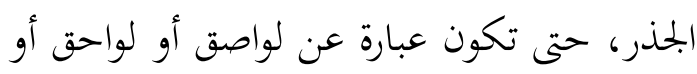

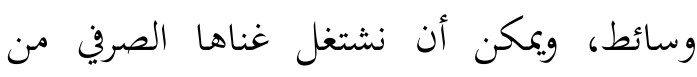

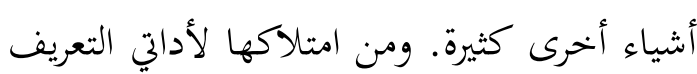
والتنكير، واللواصق الزمنية والجبرية، ولأدوات النفي والإشارة وغيرها.
اللغة العربية، بجانب الوظائف السابقة الذكرى، فلا سبيل للمسلمين عدم الإتقان كهذه اللغة العربية، لأكما لغة القرآن الكريم ولغة الأحاديث النبوية. فلا سبيل لهم الفهم بهذين المصدرين من التعاليم الإسلامية إلا بفهم هذه اللغة فهما جيدا، في علومها وقواعدها، ابتعادا عن الخطاء والغلط في فهم تعاليم هذا الدين الحنيف من مصدريها القرآن الكريم والسنة النبوية الشريفة. إن اللغة ترتقي برقي الإنسان وتنحط بانحطاطه. هذا معناه أن اللغة تتطور بتطور الإنسان، هكذا شأن جميع اللغات الموجودة في العالم. إذا كانت اللغة في المستوى العلمي، ستكون علمية وبالعكس إذا كانت في المستوى الجاهلي ، ستكون جاهلية. إذن فاللغة ترتقي برقي الحياة البشرية، لأنما هي كالناتج في الأمم. فقد قيل: لكل مقام مقال هذا معناه: المقام هو الذي يشكل اللغة في التركيب. هنا تبين لنا جليا وظيفة اللغة ومكانتها في الحياة البشرية، معرفتها ذات أهمية كبرى لشتى مرافق الحياة، لأن باللغة ترتقي بجياة الشعب وهما أيضا تنحط. فما للإنسان أن يهمل ويتساهل بكا أبد الدهر.

\section{اللغة العربية ومميزاتما}

تميزت اللغة العربية بالوضوح في مفردات ألفاظها، كما تميزت بذلك في تراكيبها، فإذا كان هناك لفظ واحد يختلف في مدلوله، فإن العربية حرص منها على الوضوح، وعدم اللبس 
للغة العربية أن تدعى سيدة اللغات كمالا وجمالا

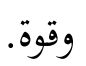

اللغة العربية البجيدة حظيت الفصحى منها

عناية فائقة واهتمام كبير من غير أصحايجا. واتخذوا للحفظ على كيانة كل وسيلة، في التعبير هما بأجمل البيان وأحسن الأداء. وذلك بمراعاة القراءة وفقا بأداء الحروف المطلوبة في مخارجها وصفاتما، فجاء ما يسمى بعلم التجويد أو علم الأصوات.

\section{الترادف في اللغة العربية}

قد جرت في اللغات الحية، منها اللغة

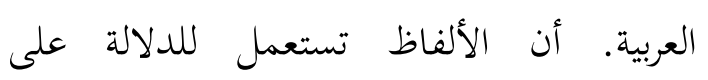
مسميات مختلفة تشترك في تلك الصفة أو ذلك الك المعنى العام. فكلمة دليل مثلا، يقصد بما من يدل على الطريق أو من يطوف على السياق ليدهم

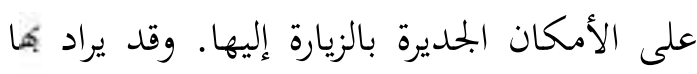

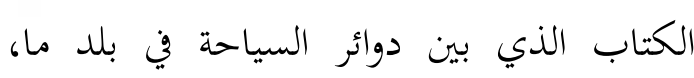
لدلالة الغريب على معالمه وآثاره. كما يقصد كذذه الكلمة الحجة المنطقية والبرهان لجميع هذه المسميات ينطبق عليها لكونها دالة لقاصدها. وإن كانت هي في ذائما نختلفة. نحن نعتقد أن نتعدد معاني اللفظ ظاهرة لغوية بندها في جميع اللغات

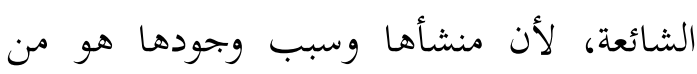
طريقة تسمية الأشياء ووضع الألفاظ وهو أمر عام في اللغات الشائعة، هذه الظاهرة هي التي سماها علماء اللغة بالاشتراك.
وقد تمكنت اللسانيات العربية الحديثة من

تحقيق كمية أساسية عند الباحثين في اللغة العربية من بلوغ درجة عليا في التنظير وحصر ظواهرها

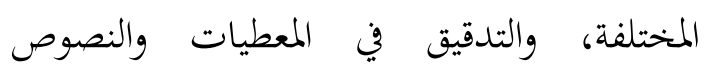
القديمة. وذلك خلصت إلى مجموعة من القواعد التي من شأكها أن تضمن سلامة هذه اللغة باعتبارها لغة القرآن الكريم ولغة الأحاديث النبوية

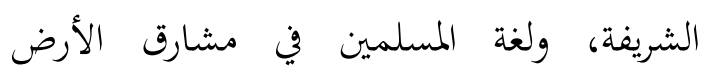
ومغاربها. وهي لغة حية بقيت ببقاء هذا الكتاب الكريم، والناس في مختلف الشعوب والأديان يدرسونها بأي غرض من الأغراض.

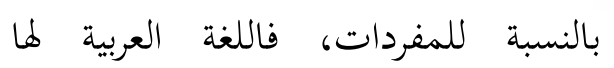

امتيازات. يقول السيوطي: "لأن لو احتجنا إلى لى لـ لهربه

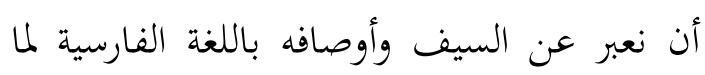
أمكننا ذلك إلا باسم واحد، ونحن نذكر للسيف بالعربية صفات كثيرة، وكذلك الأسد والفرس وغيرها من الأشياء المسميات بالأسماء المترادفات. فأين هذا من ذلك؟ وأين لسائر اللغات من من لـي السمة ما للغة العرب؟" هذا ما لا خفاء به على ولى لهن ذي فهية. فقد اجتهد علماء اللغة العربية من التأليف وتصنيف في علومها وقواعدها، سواء كانوا من العرب أو العجم. واستفاد هما الدارسون بعد، وتهوته دليلا واضحا على امتيازات هذه اللغة التي استولت على اهتمام علماء اللغات في العالم، وشدت إليها قلوشم وأفكارهم، فوجدوا أنفسهم

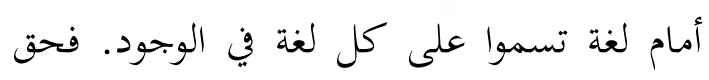


في بعض الحالات، ولا يكون كذلك في حلات أخرى. فالدلالة هي التي تدل على المعنى المقصود

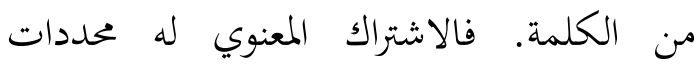
وضوابط بنيوية مضة إضافة إلى مبادئ عامة من شأثها أن الثفير هذه الظاهرة في جميع اللغات الإنسانية مككة باعتباره ظاهرة كلية .

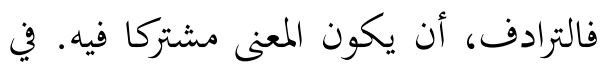

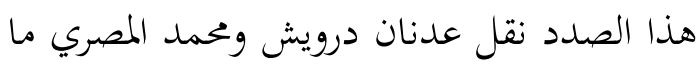

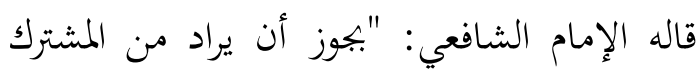

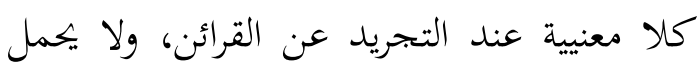

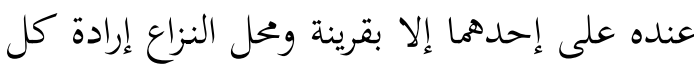
واحد من معنييه على أن يكون مرادا ومناطا

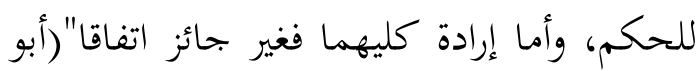
البقاء:1992 :119 ). بخصوص هذه الظاهرة اللغوية، نن نتاج إلى كثير من التدقيق، لأخما

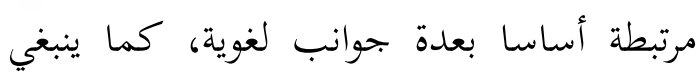

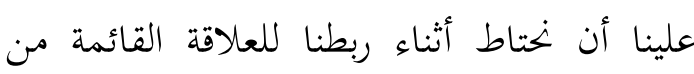
هذه جوانب. على سبيل المثال نرى الأمثلة

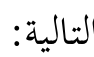
أــ ـاهدت مقابلة في كرة القدم

$$
\text { ب- نظرت إلى الأمام }
$$$$
\text { ج- رأيت رجلا }
$$$$
\text { د- م- حمقت في الرجل }
$$$$
\text { ه- - ماقبت الرجل }
$$

التصور القديم يجعل من مثل هذه الأفعال حالة على نفس المعنى، إلا أن الأمر ليس كذلك. بالرغم أن جميع هذه الأفعال تشترك في كونها
اعتبرت ظاهرة الترادف قبل الظواهر التي

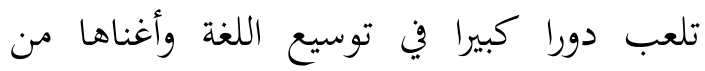
حيث اللفظ والمعنى. وقد تم الربط بين هذه الظاهرة وبين مستويات لغوية خختلفة، من الناحية

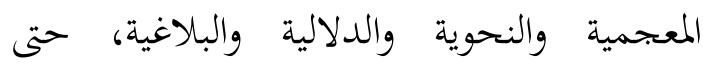
الناحية الكلامية والفقهية. وهذا ما جعل أجزاءا من التصورالعربي القديم لهم لهذه الظاهرة مشتتا بين كل هذه المباحث من اختلاف أنواعها،

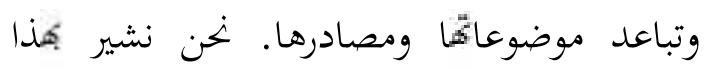
الشأن إلى أننا في هذه الدراسة سنرى الجانب

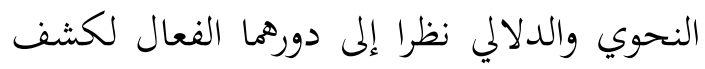
معنى المقصود من الكلمة التي دخلت في الترادف.

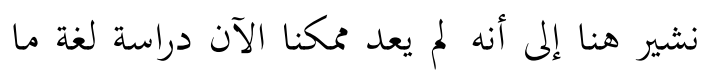

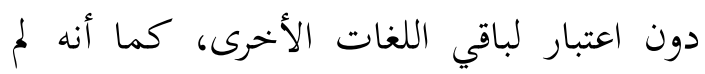
يعد بالإمكان الاكتفاء بالملاحظات الوصفية. لان دراسة اللغة تستدعي الكثير من التدقيق، ولا

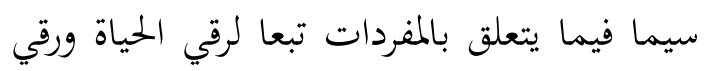
العلوم والتكنولوجيا. والمراد بالترادف هنا هو أن تدل ألفاظ كثيرة مختلفة على معنى واحد. في علم الدلالة

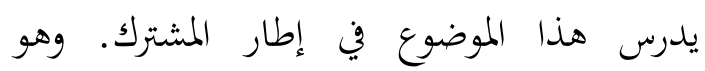
مفهموم يفيد وجود علاقة بين لفظين أو أكثر

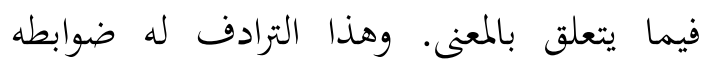
وحدوده التي لا يمكن أن يتجاوزها حتى لا يكون

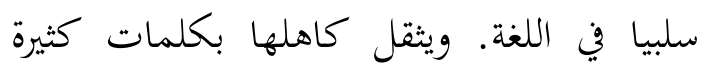
تعني نفس المعنى. مع العلم أن اللغة مثل العربية

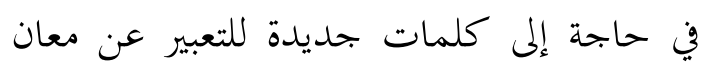
جديدة. كان الترادف في اللغة العببية يكون ممكنا 
(+ حي) أو (- حي) كما أن يكزن موجودا بالضرورة. فإنه يختلف عن الفعليين السابقين في

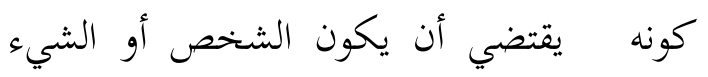
المرئي غير موجود في وضع مقابل للفاعل (يعني : للذي يرى). إذن، لتبسيط هذه الفكرة، نقول

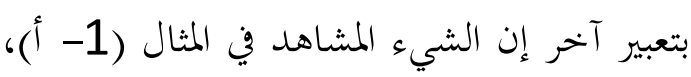

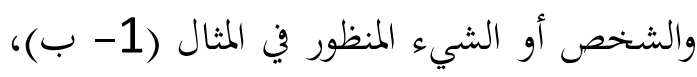

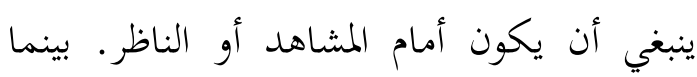
الشيء الذي يرى لا يقتضى أن يكزن أمام

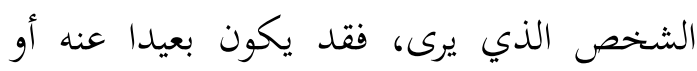

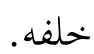

بالنسبة للفعل حملقت في المثال (1- د)،

فإنه من الأساسي أن نشير إلى أن فضلته (أي:

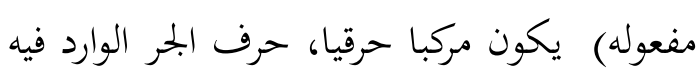

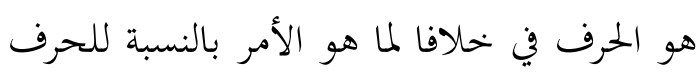

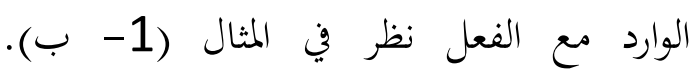
وبالإضافة إلى هذا الاختلاف التركيبي، يختلف لفران

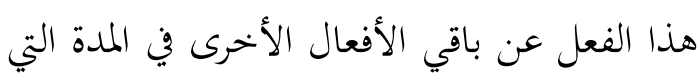
يستغرق الحديث زمنيا. هذه المدة في المثال (1-

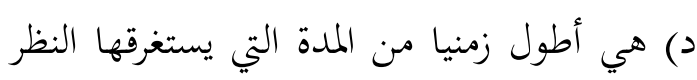

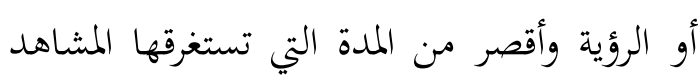

$$
\text { أو المراقبة. - مواية }
$$

أما المثل (1-هـ)، حيث مفعول راقب

يكون (+حي) فقظ. كما يكون اسما، وليس مربا حديا. وهو يختلف عن الأفعال السابقة بزمنها.

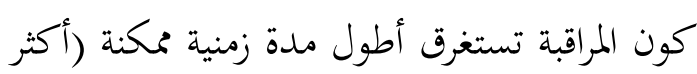

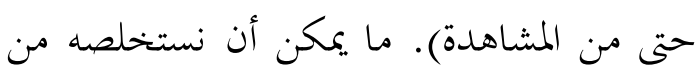
كل هذا، هو: أنه ليست هناك خصائص هلاكن لالية
بالجهاز البصري (أي: بواسطة العين). في هذا التحليل سنحاول الكشف أن الاشتراك في المعنى

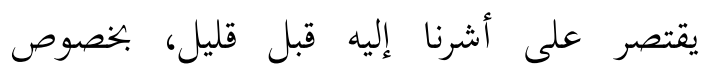

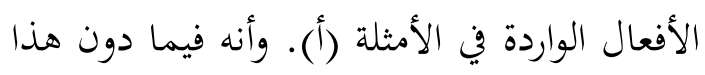
فهو فكرة غير قائمة لوجود الاختلافات الدقيقة الدانة

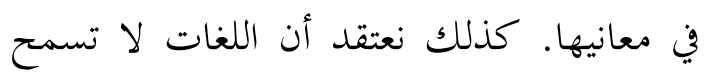

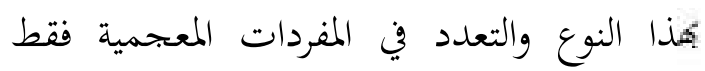

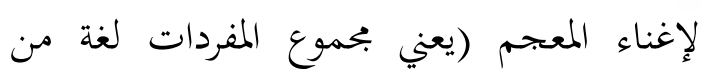
اللغات). وإنما يكون الهدف من ذلك هو التمييز

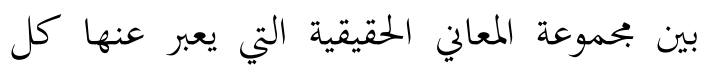
فعل من هذه الأفعال بمعزل عن الآخر. ونخن نوضح هذه الفكرة على ضوء الأمثلة (1- أ - ب)، نقول إن الفعل شاهد في المثال

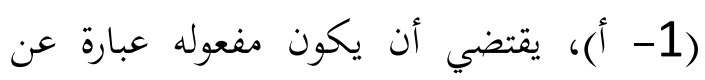

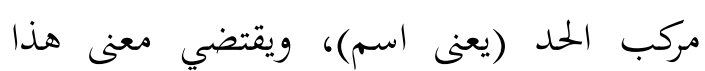

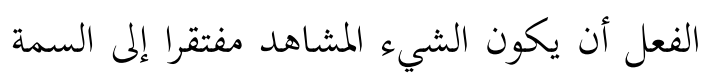

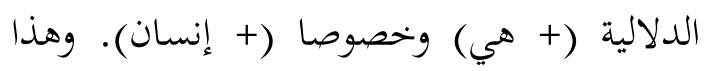
يقتضي بدوره أن يكون الشيء المشاهد موجودا

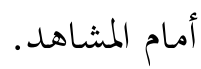
أما الفعل نظر في المثال (1 - باهد)، فهو

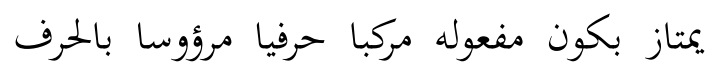

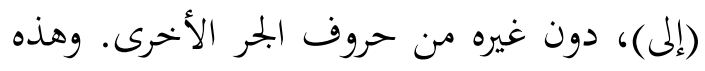
هي ميزة تركيبية تميز هذا الفعل عن جميع الأفعال

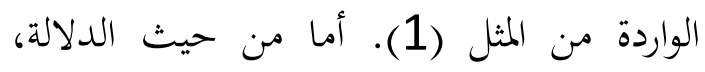
فيمكن أن يكون الشيء المنظور إليه موجودا أمام الناظر. كما هو الشأن بانسبة للفعل (شاهد).

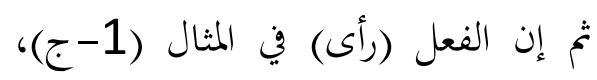
الذي يكون مفعوله عبارة عن اسم، ويكون إما لفال الفال 
هذه الأمثلة تظهر سطحيا أخا تعني نفس

المعنى. ولكن اذا بحثناها بدقة سنجد هناك الاختلاف المفترض بين المعاني التي تدل عليها هذه الألفاظ يمكن في الكيفية التي يستعمل بكا الماء. فالرش مثلا يأخذ فيه الماء شكل قطرات متنائرة، خلافا للسكب ولباقي الألفاظ الأخرى. إذا هناك فروق دقيقة بتعل هذا المعنى مخصصا همذا اللفظ دون غيره من الألفاظ الأخرى. كمذه

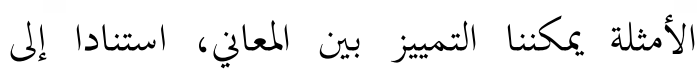
مفهوم السمات وإلى العبارات التي فيها هذه

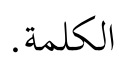

هكذا تصورنا عن الترادف في اللغة العربية. ولذلك أن هذا نوع من الظواهر اللغوية بإمكان وجودها في اللغة العربية وفي اللغات الأخرى الحية في العالم. ولكن قبل أن نأخذ بالحكم، علينا الفهم الدقيق مع مراعة السياق والدلالة التي تدل على المعنى المقصود أو على الأقل تخصيص للمعنى. وذلك لأن اللغة تعتبر من ضرورات الحياة الإنسانية، لكونها وسيلة هامة في التعاضد والتعاون والتعارف بين بني الإنسان، فالدراسة على المعنى شيئ هام أن تأخذها بعين الاعتبار. إزالة عن اللبس والغموض، ولاسيما كلمات القرآن الكريم التي فيها ظاهرة الترادف خدمة لهذا ولدي الكتاب الكريم لا ريب فيه هدى للمتقين.

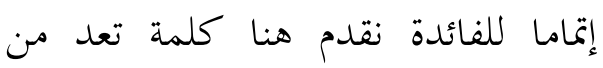
الترادف ولكن إذا دققناها الفرق مثل كلمة "الجهل والسفيه"سنرى الفرق الدقيق بين معنى الجهل والسفيه، فلا يمكن أن نقول بين هما
أو التركيبية مشتركة بين جميع هذه الأفعال. كل ما هناك هو أن بعض هذه الأفعال قد تتقاسم بعض الخصائص الدلالية ، دون أن تتقاسمها بكمالها. بكيث قد يتشائمان في السمة (+ حي) أو في كون المفعول هو اسم، ولكن هذا لا مانع من وجود خصائص أخرى مختلفة بينهما. بالنسبة للترادف في اللغة العربية، يكون ممكنا في بعض الحالات ولا يكون كذلك في حالات أخرى. وربما المعيق لهذا الإمكان أو ذلك هو السياق الذي ترد فيه هذه الألفاظ. ونظرا لافتقار الحقل الدلالي العربي لنظرية بارزة المعالم

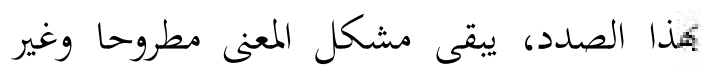

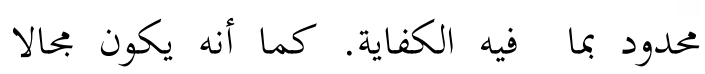
خاصا لإصدار فتوى في غياب مقاييس دلالية مبنية على أساس علمية. لهذه الأسباب ولأسباب أخرى كثيرة لا نعرف بكيفية واضحة مسوغات هذا الضرب من الاشتراك. في غالب الأحيان يكون هذا الترادف غير ممكن على مستوى المعنى، بكيث تقتضي البنية التي يظهر فيها اللفظ أن يكون هذا الأخير واسما لمعنى أو مخصصا له دون غيره من المعاني الأخرى. التي يعبر عنها بألفاظ أخرى. كما في الأمثلة التالية:

$$
\text { ثـــــــــ كب الماء }
$$


أما السفهاء فقد فى الله إتيان الأموال

إليهم وذلك لنقصان عقولهم كما في قوله تعالى: "ولا تؤتوا السفهاء أموالكم التى جعل الله لكم قياما وارزقوهم فيها واكسوهم وقولوا لهم قولا

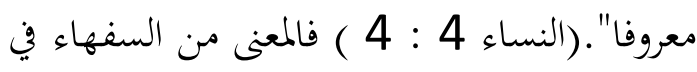
هذه الآية هو: "سيء التصرف".(محمد حسين الحمصي: 1999 : 77 ) وذلك لنقصان النهان عقولم. إذن هناك الفرق بين معنى الجهل والسفيه. فلا يمكن أن نقول بينهما مترادفان في الفئ المعنى بل لكل منهما معنى خاص. و الله اعلم. ونظرا إلى أهمية المقام في تحديد المعنى المقصود من العبارة ومن اللفظ المستعمل فيها، فالمعنى قد يتغير بحسب المقام. على سبيل المثال أستغفر الله. أستغفر فعل مضارع فاعله ضمير بلهير

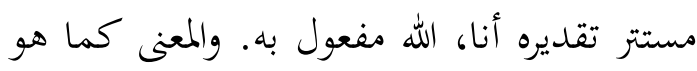

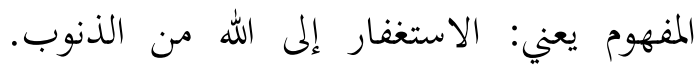

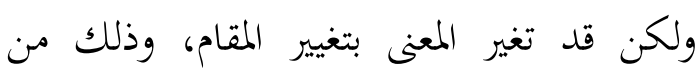
الدلالة على التعجب إلى الدلالة على السخط أو الإعجاب أو غير ذلك.

فيما يتعلق بعلاقة الدلالة بالترادف،

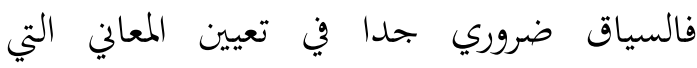
دخلت في هذه الظاهرة. وهو لا يقوم على كلمة

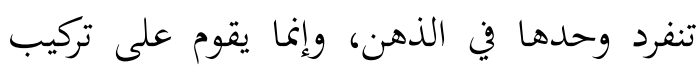

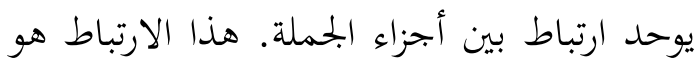
الذي يعين المعنى المناسب للفظ الذي دخل في الذياط

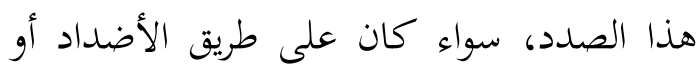

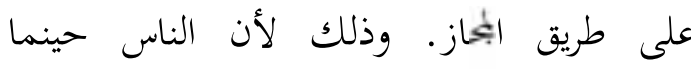
يسمعون عبارة، ويكون فيها لفظ له دلالتان
مترادفان في المعنى. فالجهل عند الراغب الأصفهاني: "على ثلاثة أضرب: الأول: وهو خلو

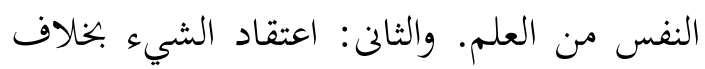

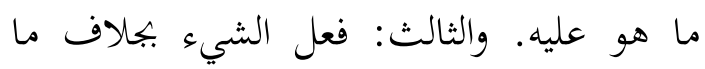

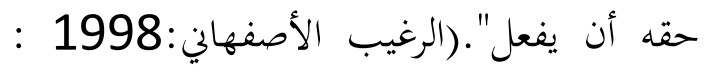

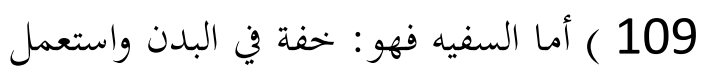
في خفة النفس لنقصان العقل، وفي الأمور الدنيوية والأخروية. فقيل "سفه تفسه وأصله سفه نفسه م فصرف عنه الفعل.(الرغيب الأصفهاني:1998 : 60 ) بند في القرآن الكريم هاتين الكلمتين في عدة آيات منها قوله تعالى: "سيقول السفهاء من الناس ما و لاهم عن قبلتهم التي كانو عليها

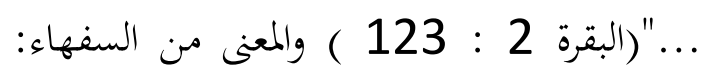
خفاف العقول (المراد: اليهود ومن شاكلهم في

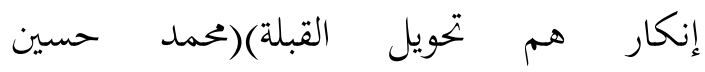
الحمصي:1999 : 22) وقوله تعالى: "وعباد

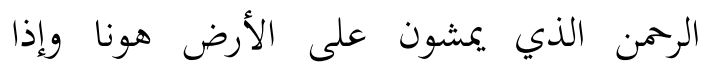
خاطبهم الجاهلون قالو سلاما".(الفرقان 63 :

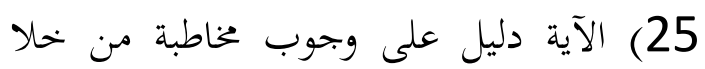
نفسه من العلم بالتحية لا بالسخرية ـ وذلك من العن كامل الأخلاق وفاضل الصفات، كما أمر الله

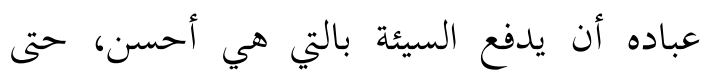
يكون بين العداوة صديقا قريبا. كما في قوله تعالى: "...ادفع بالتي هي أحسن فإذا الذي بينك هيكا. وبينه عداوة كأنه ولي حميم".(فصلت 41 : 4 : 34) فالرسول صلى الله عليه وسلم لا تزيده شدة

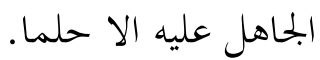


مستقلتان، يعرفون أنه من الممكن استعماله في المعنى الثلاثة، وهو الوجه الذي تتمثل فيه هذا المقصود أو في غيره. ومن هذا الخيال، نشأ العلاقات والأحداث والظروف الاجتماعية التي ما يسمى بالاشتراك. فلا نعرف المعنى من هذا تسود ساعة أداء المقال. ومن المعروف أن إجلاء اللفظ إلا بالدلالة التي تدل على ذلك المعنى المعنى على المستوى الوظيفي (الصوتي والصرفي والنحوي) وعلى المستوى المعجمي فوق ذلك لايعطينا إلا معنى المقال أو المعنى الحريف (تمام حسن:1994: 337). إذن لمعرفة المعاني التي

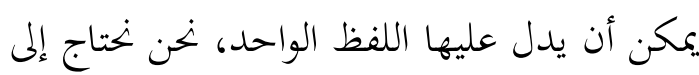
فهم المقام الذي يقال فيه اللفظ المقصود، إضافة

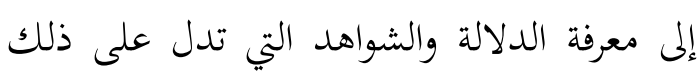
المعنى. هنا تتجلى واضحا العلاقة الوطيدة بين الاشتراك والدلالة. - ملئ.

القرينة ذات أهمية كبرى في تعيين المعنى من اللفظ، لذلك فهم المقام على ضوء المقال شيء ضروري للوصول إلى المعنى الصحيح من العبارة. على سبيل المثال لفظ كل فعل أمر يتغير معناه إلى النهي بحسب المقام الذي يقال فيه هذا

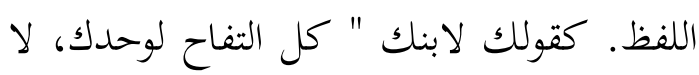
تدع أخاك بأكله" هذه العبارة قالها الأب لولده وهو غضب عنه، لأنه خالف نصيحته. وهي ألا يأكل التفاح لوحده إلا مع أخيد. فالأمر هنا بمعنى النهي على حسب المقام الوارد في هذه العبارة. ولو كان كذلك، إن الاعتماد على المقال فحسب لا يكفى في فهم اللفظ، دون النظر إلى المقام وإلى السياق من الكلام وإلى الدلالة التي تدل على المعنى المقصود. بل يؤدي أحياناإلى الخطأ والغلط في الفهم. ولا سيما في فهم الآيات القرآنية التي فيها كلمات لفهمها يحتاج إلى المقام

ويقول ممد منظور كما قدمه الأستاذ

صلاح الدين الندوي الأزهري في محاضرته: "إن الكلمات هلا أرواح يجب أن تضرب. الكلمة كالكائن الحي والكائن الحي له شخصيته، هذه الشخصية لا ترى في القواميس والمعاجم العربية، رغم وجود مترادفات. لكن هذه الكلمات التي يختار منها الأديب كلمة دون كلمة، فلا ترادف لما في عباراته أو في صيغ عباراته من حيث الصيغ.(صلاح الدين الندوي: 2001) من هنا تبين لنا أننا لانفهم المعنى من الكلمة بدون الرجوع إلى عدة علوم تتعلق بكذا المعنى منها علوم اللغة التي تتعلق بظاهرة الترادف وكذلك بمعرفة الدلالة التي تدل على هذا المعنى المقصود. بالنسبة للغة العربية تعدد ألفاظ بمعنى واحد من مميزات هذه اللغة اليخيدة التي هي لغة كتاب الله الكريم.

\section{عالاقة الترادف بالدلالة}

بالنسبة للدور الذي يلعبه المقام في تعيين المعنى من اللفظ قال تمام حسان: "وفكرة المقام هذه هي المركز الذي يدور حول علم الدلالة

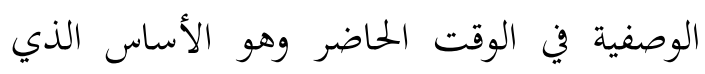
يبنى عليه الشق أو الوجه الاجتماعي من وجوه 
من البحوث السابقة بالامكان أن نصل إلى الخلاصة التالية:

1. اللغة العربية تطورت بتطور الزمان والمكان، وهي بقيت ابد الدهر ببقاء القرآن الكريم الذي أنزله الله على رسوله الهي الدهر بهاء

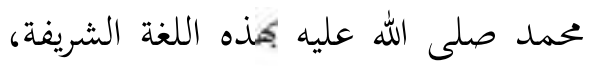

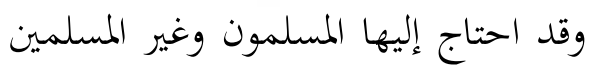
في أمور شتى، فصارت من اللغات الرسمية

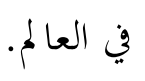

2. الإنسان مدني بالطبع، فلا يمكن أن

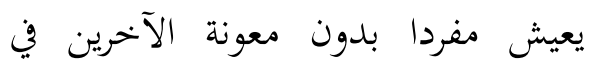
التعبير ما خطر في باله لسد ما يحتاج إليه في تكميل لوازمه الدنيوية والأخروية، بغية

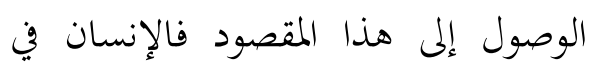
حاجة شديدة إلى اللغة، فلا سبيل له

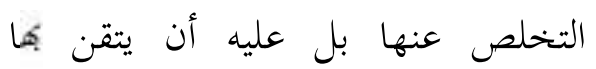

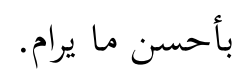

3. للغة العربية ميزات مالم يوجد في اللغات

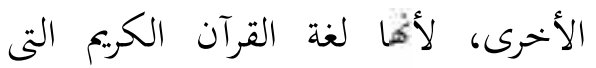

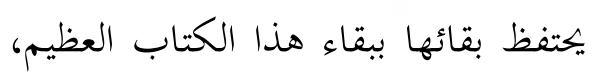

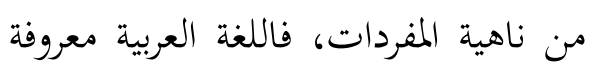
بكثرة المفردات وسعة التعبير حتى تمكنت المعردات فالعة العربية اللسانيات العربية الحديثة من تحقيق العبردير تمكنت أساسية عند الباحثين في هذه اللغة ببلوغ درجة عليا في التنظير وحصر الظواهر المختلفة كمثل الترادف الذي لئي
والدلالة. على سبيل المثال ننظر ما حدث عند ما

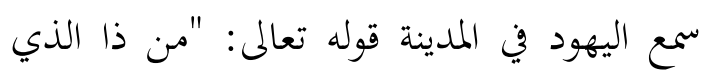
يقرض الله قرضا حسنا فيضاعف له وله أجر كريم

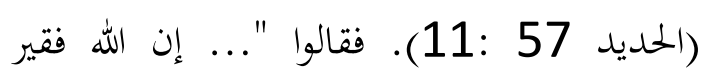
ونحن أغنياء (آل عمران 3: 181 ) ) ..." نظرا لفالحا

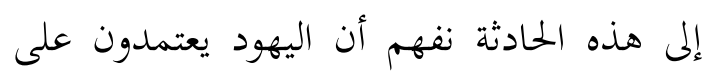
المقال، ويريدون أن يطفئوا نور الله بأفواههم. المعنى من قوله تعالى: "يقرض الله" هو ينفق ماله

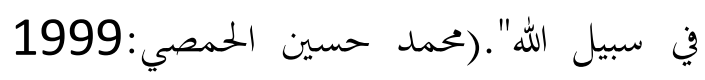
( 538:

بجانب العلاقات الصرفية بين المفردات ومعانيها والدور الذي يعلب في تعيين المعنى

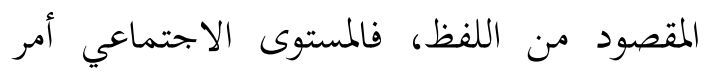

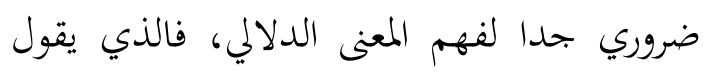
لفرسه عندما يراها، أهلا بالجميلة. يختلف المقام الملام هالدي يقول

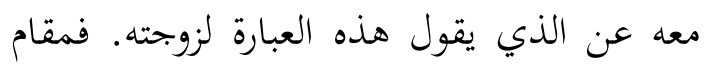
توجيه هذه العبارة للفرس. هو مقام الترويض.

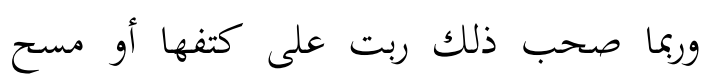

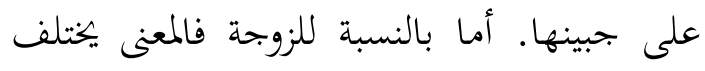

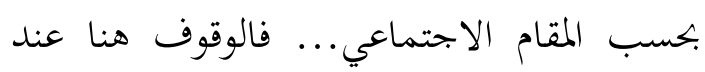

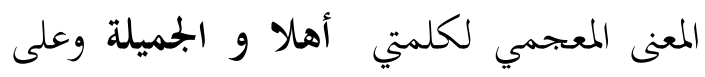

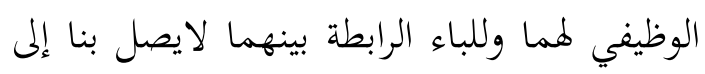

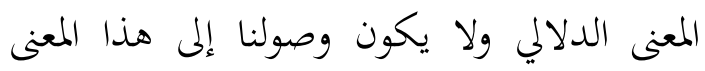
الدلالي إلا بالكشف عن المقام الذي قيل فيه 
8. محد حسين الحمصي، تفسير وبيان مفردات القرآن( بيروت : مؤسسة الإيمان

$$
1999 \text { م)، ط 1، ص } 10
$$

9. سورة يوسف 12: 111 10. سورة الحجرات 13: 49 11. حنا الفاخوري، تاريخ الأدب العربي المكتبة

$$
\text { (بيروت: منشورات }
$$

البوليسية، 1987 ) ص، 25

12. أبو البقاء أيوب بن موسى الحسني الكوفي

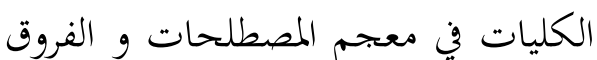
اللغوية تحقيق عدنان درويش ومحمد المصري، (بيروت المؤسسة الرسالة

$$
\text { 1992) ص } 119
$$

13. الرغيب الأصفهاني، المفردات في غريب القرآن، ضبطه وراجعه محمد خليل عيتاني،

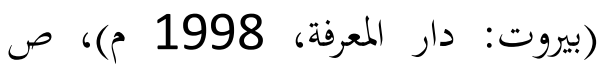

$$
\begin{aligned}
& \text { 14. نفس المرجع، ص. } 60 \\
& \text { 15. سورة البقرة 2: } 123 \\
& 22 \text { ص }
\end{aligned}
$$

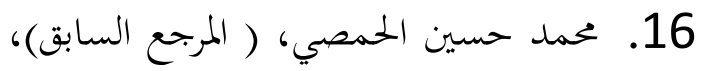

17. سورة الفرقان 63: 25

18. سورة فصلت 41: 34

19. سورة النساء 4: 4 20. محد حسين الحمصي، (المرجع السابق)، 77 ص

21. صلاح الدين الندوي الأزهري، من محاضرته في الأدب المقارن، برنامج
4. الترادف من ظاهرة اللغة وهو موجود في اللغة العربية حتى في اللغات الحية في العالم ولكن لا يمكن أن نقول هناك ترادف كلي بل ترادف جزء أو تخصيص لون

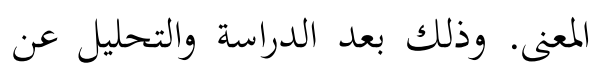

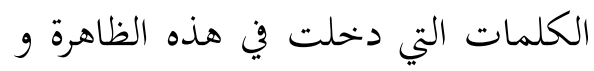
استنادا إلى السمات والعبارات التي فيها هذه الكلمة وإلى الدلالة التي تدل على إلى التيار فئل المعنى المقصود. في هذا الصدد نرى جليا علاقة متينة بين الترادف والدلالة.

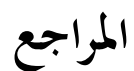

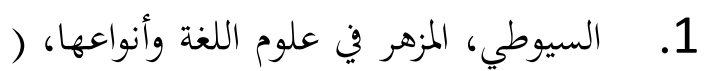

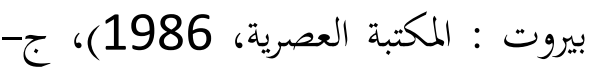

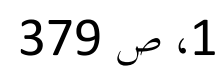

2. مصطفى صادق الرافعى، إعجاز القرآن والبلاغة النبوية، (بيروت: دار الكتاب إناب العرات العربي، 1973)،ط 9، ص 315 3. سورة يونوس 10: 57-58 4. سورة الحجر 10: 9 5. 5 ابراهيم السامراني، فقه الللغة المقارن،

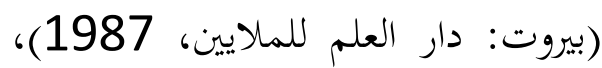
ط 4، ص (يروت نار 28 6. محمد السعران: اللغة والبختمع ( مصر: دار المعارف 1923) ص 12 7. سورة البقرة 2: 77 
126 Ta'dib, Volume 14, No. 2 (Desember 2011)

$$
\begin{aligned}
& \text { الدراسات العليا جامعة شريف هداية الله 23. سورة الحديد 57: } 11
\end{aligned}
$$

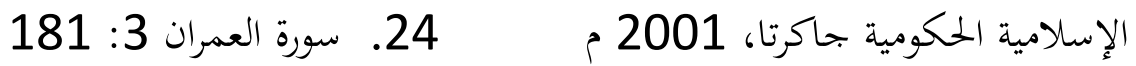

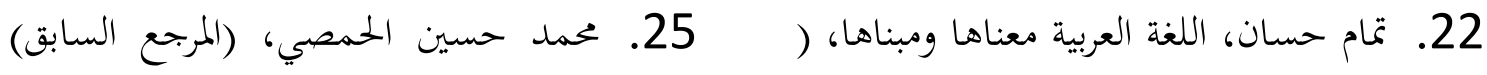

$$
\begin{aligned}
& \text { الدار البيضاء: دار الثقافة للنشر والتوزيع، 5 }
\end{aligned}
$$

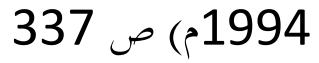

